\title{
La lucha por el derecho a decidir en Quintana Roo: Avances, obstáculos y retos
}

\author{
The Fight for the Right to Decide in Quintana \\ Roo: Progress, Obstacles and Challenges
}

Fecha de recepción: 08/09/2021

Fecha de aceptación: 29/11/2021

Fecha de publicación: 07/03/2022

https://doi.org/10.48102/if.2022.v2.n1.204

\section{Yunitzilim Rodríguez Pedraza*}

yunitzilim@uqroo.edu.mx; yunitzilim@outlook.com

ORCID: https://orcid.org/0000-0002-7329-2169

Doctora en Derecho Constitucional y Amparo

Universidad de Quintana Roo

México

\author{
Erika Lizbeth Cornelio Ramos** \\ erika_kornelio@hotmail.com \\ Maestra en Políticas Públicas Comparadas \\ Universidad Modelo de Chetumal \\ México
}

\begin{abstract}
* Yunitzilim Rodríguez Pedraza es profesora investigadora de tiempo completo de la Academia de Ciencias Jurídicas de la División de Ciencias Sociales y Derecho de la Universidad de Quintana Roo. Licenciada en Derecho por la Universidad de Quintana Roo (UQROO). Maestra en Derecho Constitucional y Amparo por la Universidad Iberoamericana Campus Golfo Centro. Doctora en Derecho por la Universidad Popular Autónoma de Veracruz. Candidata a Investigadora del Sistema Nacional de Investigadores (SNI). Sus líneas de investigación son derechos humanos, género, Estado y seguridad pública.

** Erika Lizbeth Cornelio Ramos es catedrática en la Universidad Modelo de Chetumal. Licenciada en Relaciones Internacionales por la Universidad de Quintana Roo (UQROO) y maestra en Políticas Públicas Comparadas por la Facultad Latinoamericana de Ciencias Sociales (FLACSO); actualmente se encuentra cursando la licenciatura en Derecho en la Universidad Autónoma de Chiapas (UNACH). Sus líneas de investigación son enfoque de género, políticas públicas y derechos humanos.
\end{abstract}




\author{
Claudia Guadalupe Sánchez Martín*** \\ psicologa_claudiamartin@hotmail.com \\ Licenciada en Psicología \\ Marea Verde Quintana Roo \\ México
}

\title{
Resumen
}

La lucha por el derecho a decidir en Quintana Roo se ha dado desde diversos espacios y con múltiples acciones: desde la academia, en la producción intelectual y las aulas; desde el activismo de calle, con marchas y manifestaciones; desde el actuar de colectivas en mesas de trabajo con el Gobierno para impulsar una agenda de género; con iniciativas ciudadanas para lograr la despenalización del aborto ante los órganos legislativos; con posicionamientos y pronunciamientos públicos respecto a las omisiones del Estado en la protección, garantía y respeto del derecho a decidir; desde foros en los que se plantea la necesidad de una educación integral de la sexualidad para que abortar sea considerado como parte de los derechos sexuales y reproductivos de las mujeres y una extensión del derecho a la salud.

Hasta el día de hoy, el Estado no ha sabido respetar el derecho a la protesta y a la libre manifestación de las ideas, por lo que todas las luchas y acciones de las mujeres quintanarroenses han traído aparejadas la criminalización y la estigmatización cada vez más fuerte hacia quienes se han posicionado abiertamente como feministas y acompañantes de interrupciones de embarazos no deseados. No obstante, una cara de la pugna por los derechos humanos que ha significado un hecho histórico han sido la lucha por lograr el derecho a decidir desde la capital de la entidad, la toma pacífica del Congreso del Estado de Quintana Roo, así como la puesta de la Antimonumenta en memoria de las víctimas de feminicidios.

\footnotetext{
*** Claudia Guadalupe Sánchez Martín es activista integrante de Marea Verde Quintana Roo. Licenciada en Psicología por la Universidad de Valladolid Yucatán (UVY). Pasante de la maestría en Género, Derecho y Proceso Penal en el Centro de Estudios de Posgrado. Pasante de la especialidad en Victimología por el Instituto Colimense de Ciencias Forestes. Posee formación académica en Psicología Jurídica y Clínica. Actualmente realiza práctica privada en atención psicológica y acompañamiento a víctimas. Es docente en posgrado y licenciatura, así como tallerista y capacitadora externa con registro ante la Secretaría del Trabajo y Previsión Social. Acompañante en atención psico-jurídica y acompañante psicológica. Promotora y defensora de los derechos humanos de las mujeres.
} 


\section{Palabras clave}

Toma pacífica, Antimonumenta, feministas, aborto, maternidad deseada.

\section{Abstract}

The struggle for the right to decide in Quintana Roo has taken place in different spaces and with multiple actions: from academia, in intellectual production and the classroom; from street activism, with marches and demonstrations; from the actions of collectives in working groups with the government to promote a gender agenda; with citizen initiatives to conquer the decriminalization of abortion before legislative bodies; with positions and public pronouncements regarding the State's omissions in the protection, guarantee and respect for the right to decide; from forums in which the need for comprehensive sexuality education is raised so that abortion is considered as part of women's sexual and reproductive rights and an extension of the right to health.

To this day, the State has not been respectful of the right to protest and the free expression of ideas, so that all the struggles and actions of women in Quintana Roo have brought with them criminalization and increasingly strong stigmatization of those who have openly positioned themselves as feminists and those who accompany the interruption of unwanted pregnancies. However, one side of the struggle for human rights that has meant a historic event has been the struggle to achieve the right to decide from the capital of the state, the peaceful takeover of the Congress of the State of Quintana Roo, as well as the installation of the "Antimonumenta" in memory of the victims of femicides.

\section{Keywords}

Peaceful taking, Antimonumenta, feminists, abortion, desired motherhood.

\section{Introducción}

No se puede entender el movimiento feminista que irrumpe en Quintana Roo si no se sitúa en el contexto al que pertenecen y en el que residen sus integrantes: América Latina, el sur del continente americano y el sureste de México.

Si se parte de que el feminismo es un movimiento social crítico que, a través de su intervención concreta, se sitúa en permanente confrontación y diálogo con el sistema en el que se inserta, no se puede entender como un movimiento monolítico, sino todo lo contrario, ya que 
en él confluyen de manera simultánea diversas corrientes feministas e incluso diversas concepciones teórico-políticas dependiendo de la sujeta que lo habla o lo relata.

Así pues, el movimiento feminista en Quintana Roo se ubica en el ámbito de la disidencia y en ser un contestario constante del sistema patriarcal que hoy prevalece en las instituciones y en todos los espacios; es, sobre todo, un movimiento que se asume y pertenece al sur y desde el sur.

En este contexto, es importante situarse en el feminismo decolonial; esto obliga a pensar desde el sur y desde los cuerpos racializados, pues las integrantes emergen en gran medida del feminismo comunitario y los pueblos originarios, como el pueblo maya.

Los feminismos pensados desde América Latina, como lo señala Nora Garita (2019), "recuperan entramados comunitarios que permiten pensar y re-pensar el individualismo de los feminismos hegemónicos e incorporar la relación con la Naturaleza" (p. 14). Esto significa que las mujeres, desde el feminismo, se piensan y realizan acciones desde la colectividad y la comunidad; no desde la individualidad de sus actos.

El activismo en América Latina en pleno siglo XXI se caracteriza por las mujeres jóvenes que lo integran, quienes son las principales protagonistas de dichos movimientos y han trasformado la incidencia política, las agendas e incluso la forma de hacer activismo.

Las mujeres que hoy hacemos incidencia, como las morras en todo México, integramos principalmente colectivas y nos volcamos a participar en "marchas y peticiones, huelgas y tomas de instituciones educativas [y de gobierno], debates en los espacios virtuales, denuncias públicas frente a abusos, 'escraches' a violentos y abusadores" (Larrondo y Ponce, 2019, p. 22).

Las colectivas feministas, así como hablan del acoso y el hostigamiento sexual, la violencia digital, las desigualdades salariales, la denuncia en torno al acoso laboral y callejero, el derecho al acceso al aborto, la visibilidad y el reconocimiento de las disidencias sexuales, entre otras demandas, también hablan de los feminicidios, de las diversas violencias que atraviesan a las mujeres, del empoderamiento y de la incidencia política. A esto se suma su clara vocación pluricultural y étnica, en especial para las hermanas mayas, cuyas condiciones históricas y estructurales de desigualdad hoy las mantienen en condiciones sociales y económicas de vulnerabilidad y marginación socioeconómica. 
Para Quintana Roo, septiembre de 2018 es una fecha que representó un parteaguas en la lucha por la despenalización del aborto. Desde años atrás, muchas mujeres estaban convencidas de la importancia del tema, realizaban acciones desde sus trincheras para tratar de incidir mientras luchaban contra el estigma en una sociedad conservadora, tradicionalista, misógina y machista.

En 2018, inspiradas por la Marea Verde Argentina, se conformaron nuevas colectivas en la entidad, lo que posibilitó que quienes estaban a favor del derecho a decidir pudieran conocerse, identificarse y articularse, creando redes más grandes y fuertes.

Con el tiempo - y dados algunos eventos lamentables en la entidad-, 1 en 2020 esa articulación se convirtió en la Red Feminista Quintanarroense (RFQ) que, si bien no reunió a todas las feministas del estado, sí representó a la mayoría de aquellas organizaciones de la sociedad civil y colectivas que pusieron sus cuerpos, tiempo, conocimientos, trayectoria, talento, experiencia, recursos, pasión y alma para avanzar hacia mejores condiciones de salud, educación, justicia, igualdad y paz para las mujeres en el territorio.

El trabajo ha sido arduo y ha costado mucho puesto que, desde que se posicionan abiertamente a favor de maternidades deseadas, estas mujeres son más identificables y eso las hace objeto de criminalización no sólo por parte de la sociedad sino también por parte del Estado. De todo ese trayecto lleno de obstáculos, pero también de muchas satisfacciones, es que se hablará en el presente artículo.

\section{Marea Verde Quintana Roo. 2018}

Una de las colectivas creadas en ese año fue Marea Verde Quintana Roo, la cual lanzó su página de Facebook el 10 de septiembre de 2018 e integró a la marea a quienes se identificaban con el movimiento, independientemente de que ya estuvieran incorporadas y organizadas en otras colectivas $u$ organizaciones, con la idea de crear redes de apoyo y acompañamiento cada vez más amplias.

Así, las mujeres en Quintana Roo tuvieron la oportunidad de acceder a información para eliminar los mitos creados alrededor del aborto y

1 Como los feminicidios ocurridos en la entidad y la brutal represión policiaca en Cancún el 9 de noviembre de 2020 hacia las personas que se manifestaban por el feminicidio de la joven Alexis. 
acceder a una interrupción voluntaria con pastillas, ya sea estableciendo comunicación mediante los sitios web o al identificar a alguna feminista cercana.

Como nunca antes, el tema se puso en la mesa de discusión, no sólo legislativa sino también y principalmente en la social, puesto que abiertamente nadie se había atrevido a plantear la violación a los derechos humanos -específicamente a los derechos sexuales y reproductivos- y la forma en la que, en la entidad, se sancionaba a quienes accedían a un aborto.

Se planteó la urgencia y la necesidad de cambiar el marco jurídico estatal, el cual no se ajustaba ni a los estándares internacionales de protección de los derechos humanos ni a la Constitución Federal. Por ello, el 24 de septiembre de 2018, la colectiva Marea Verde Quintana Roo presentó - con el respaldo de muchas personas - una "Iniciativa [ciudadana] de Decreto por el que se reforman, adicionan y derogan diversas disposiciones de la Constitución Política del Estado Libre y Soberano de Quintana Roo; el Código Penal para el Estado Libre y Soberano de Quintana Roo; y la Ley de Salud del Estado de Quintana Roo" ante el Congreso del Estado de esa entidad para lograr la interrupción del embarazo sin penalización hasta antes de la decimosegunda semana de gestación, así como para asegurar la prestación del servicio en el sector salud de manera segura y gratuita, exigiendo, por lo menos, los mismos derechos de los que gozaban en ese entonces las mujeres que vivían o podían trasladarse a la Ciudad de México.

Una vez decidida la estrategia, el 26 de septiembre de 2018 se convocó a una conferencia de prensa para dar a conocer el contenido de la iniciativa ciudadana presentada, así como para convocar a las mujeres a participar en la primera marcha por el aborto legal, seguro y gratuito, a celebrarse en la capital del estado (Chetumal) el 28 de septiembre de 2018 en el marco del Día Global por la Despenalización del Aborto en América Latina y el Caribe. La marcha partió del Museo de la Cultura Maya hacia la explanada de la bandera, en donde se encuentra el Palacio de Gobierno. Las mujeres salieron a las calles a gritar y a exigir al Estado que dejara de criminalizarlas.

Es importante mencionar que Quintana Roo tiene una Declaratoria de Alerta de Violencia de Género contra las Mujeres (AVGM) desde el 7 de julio de 2017, de la cual se derivó el compromiso del ejecutivo del 
estado de realizar una armonización legislativa con perspectiva de género en el territorio. ${ }^{2}$

Varias mujeres se reunieron, organizaron, asumieron tareas y responsabilidades para antes y el día de la marcha; por ejemplo, compraron tela verde, la cortaron a la medida y mandaron imprimir pañuelos con el texto "Educación sexual para decidir; anticonceptivos para no abortar; aborto legal para no morir" para así identificar la lucha y el movimiento.

Se efectuó la marcha con una gran afluencia, contrario a lo que muchas personas pronosticaban. Hubo principalmente personas jóvenes del sexo femenino - aunque también algunas del sexo masculino- y personas adultas mayores que formaron el amplio contingente. En las pancartas y carteles se podían observar consignas como "Saquen sus rosarios de nuestros ovarios", "Mi cuerpo, mi decisión", "La maternidad será deseada o no será", "En mi cuerpo, sólo mando yo". Aun cuando hoy parezcan frases comunes en marchas a favor del derecho a decidir, en ese momento significaba un gran avance por haber sido la primera marcha sobre el tema en Quintana Roo. Los medios de comunicación transmitieron en vivo; algunas fotógrafas y fotógrafos tomaron capturas de la marcha y de sus asistentes; había una energía de fuerza y unión maravillosa. Fueron momentos históricos para una ciudad como Chetumal.

Pero levantarse como nunca antes, salir a las calles, gritar y mostrar las exigencias sobre todo en un tema controversial trajo una serie de señalamientos, exhibición, críticas, insultos, humillaciones y amenazas a quienes participaron en la conferencia de prensa, a quienes se atrevieron a portar el pañuelo verde, a quienes convocaron a la marcha mediante la página de la colectiva Marea Verde Quintana Roo y más aún para quienes fueron y aparecieron en la transmisión en vivo o en las fotos tomadas, publicadas

2 La Alerta de Violencia de Género contra las Mujeres (AVGM) es un mecanismo de coordinación interinstitucional que pretende establecer medidas urgentes para la prevención y atención de contextos de violencia contra las mujeres, establecido en la Ley General de Acceso de las Mujeres a una Vida Libre de Violencia. En el estado de Quintana Roo, se decretó la AVGM el 7 de julio de 2017 para los municipios Benito Juárez, Cozumel y Solidaridad; asimismo, requiere acciones específicas para el municipio Lázaro Cárdenas, municipio de población indígena. Entre otros puntos, la alerta mandata la armonización de la legislación estatal bajo los estándares internacionales (véase Comisión Nacional para Prevenir y Erradicar la Violencia Contra las Mujeres, 2016). 
y difundidas. Fue ahí cuando las posturas de antiderechos y los ataques se incrementaron.

Si algo quedó demostrado es que, una vez que una mujer logra salir de la opresión y levanta la voz, difícilmente se deja acallar; sobre todo si sabe que hay muchas otras mujeres al lado y delante de ella para apoyarla y sostenerla, para poner el cuerpo, para gritar juntas, para caminar lado a lado y para acompañarla si decide interrumpir su embarazo.

Ante la postura firme y el aumento de personas que se integraban a las colectivas, hubo reacciones por parte de los grupos antiderechos, que contaron con la anuencia e incluso con el patrocinio del Estado. En la página de Facebook de la Fundación Siiniko'ob - relacionada con una escuela privada religiosa en la ciudad-, se publicitó un cartel de difusión del evento denominado 1. ${ }^{\text {er }}$ Foro de Jóvenes y Familias con Valores, a efectuarse el 12 de octubre de 2018 en el auditorio de la Universidad de Quintana Roo (UQROO).

Los carteles de difusión, videos en Facebook y spots de radio mostraban logos y mencionaban el nombre de la Secretaría de Educación de Quintana Roo (SEQ), la UQROO, Comisión Estatal de los Derechos Humanos de Quintana Roo (CEDHQROO) y el Instituto de Administración Pública de Quintana Roo (IAPQROO), entre otros, como las instituciones que los apoyaban y respaldaban; incluso, estuvieron presentes representantes de dichas instancias en el momento de la presentación del evento.

La difusión del foro se intensificó después de la marcha del 28 de septiembre. Tras la intervención de algunas colectivas que cuestionaron y denunciaron la participación de diversas instituciones en un evento antiderechos, modificaron algunos de sus carteles y mantuvieron únicamente los de la fundación y asociación; sin embargo, los videos y spots seguían señalando el apoyo de las instituciones del Estado.

Algunas de las integrantes de las colectivas feministas tuvieron la obligación de asistir al evento - para quienes trabajaban en dependencias del sector educativo era obligatorio- y pudieron observar que la información que se dio estuvo basada totalmente en la religión. En algún momento, se mencionó que quienes no tenían valores cometían errores como el que se mostraba en la pantalla, en la que se proyectó una fotografía de un producto en la etapa final de su formación (por lo menos de veinticuatro semanas de gestación) con la intención de inferir odio, intolerancia y repulsión hacia el aborto seguro, legal y gratuito por el que se estaba y se sigue 
luchando a nivel estatal, nacional e internacional, incentivando los señalamientos en contra de quienes luchan por ese derecho, creando confusión en los y las presentes -en el caso del público que asistió en la mañana, sus edades oscilaban entre los quince y los veintitrés años-.

El evento fue fuertemente cuestionado por las colectivas feministas; incluso se interpuso una queja ante la Comisión Nacional de Derechos Humanos (CNDH) pues se consideró urgente y necesario el manejo de una información laica, científica y veraz en materia de educación sexual para no crear confusión en una cuestión urgente de regulación para la protección de los derechos humanos como lo es el acceso a un aborto seguro, legal y gratuito, aunado a que, a partir del inicio de actividades aún más contundentes del movimiento y sobre todo después de la marcha efectuada en septiembre de ese mismo año, en el que sus integrantes fueron objeto de denostaciones, ofensas, señalamientos y amenazas directas de violencia en las redes sociales, quedaba demostrada la intolerancia, la poca o nula información veraz que se tiene sobre los derechos sexuales y reproductivos, el grado de enraizamiento de los estereotipos de género y el grado de violencia generalizada hacia la mujer en el estado de Quintana Roo. En este contexto, este tipo de eventos sólo incentivaba la campaña de odio hacia las feministas.

Se debe recordar que el artículo 3 constitucional que regula el derecho a la educación, relacionado con el artículo 24 que garantiza la libertad de creencias, determina que la educación debe ser laica y, por lo tanto, debe mantenerse por completo ajena a cualquier doctrina religiosa; la educación debe orientarse bajo un criterio basado en los resultados del progreso científico y debe luchar contra la ignorancia y sus efectos, las servidumbres, los fanatismos y los prejuicios.

El artículo 3 también señala que la educación debe contribuir a la mejor convivencia humana, a fin de fortalecer el aprecio y respeto por la diversidad cultural, la dignidad de la persona, la integridad de la familia, la convicción del interés general de la sociedad, los ideales de fraternidad e igualdad de derechos de todos, evitando los privilegios de razas, de religión, de grupos, de sexos o de individuos.

De tal manera que el foro efectuado no cumplió con ninguno de los objetivos planteados en la carta magna -aunque fue respaldado y patrocinado por dependencias del Estado-, exponiendo ante las y los adolescentes imágenes fuera de la realidad y sin ningún contexto o mensaje de 
contención que les permitiera procesar la información que se les proporcionó, clausurando el derecho a decidir mientras que el Estado mismo no proporciona una educación integral de la sexualidad.

Al final, este evento fue parte de una campaña de tergiversación de la información verídica y científica sobre la interrupción del embarazo; la campaña alentó el odio y la intolerancia en contra de quienes luchan por el aborto seguro, legal y gratuito; generó confusión y estigmatización, y creó mitos falsos respecto a la problemática, basándose en información falsa y, sobre todo, con apoyo y participación del Estado.

En la queja interpuesta, se insistió en que ninguna institución pública o espacio al servicio de las y los quintanarroenses - universidades públicas, hospitales, centros de salud- sean utilizados para desinformar, atentar contra el Estado laico e incitar al odio en temas centrales para la vida de las mujeres y sus derechos.

Aun cuando se solicitó que se hiciera público el origen del financiamiento para la realización del evento - debido a que involucra a una universidad pública obligada a cumplir el principio constitucional de laicidad-, que se diera a conocer cuál fue la participación de la SEQ, la UQROO, la CEDHQROO y el IAPQROO y que se responsabilizaran de su actuación, hasta el momento no han proporcionado respuesta a ello.

Desde ahí, el movimiento a favor del aborto empezó a incomodar más de lo que ya lo había hecho con la marcha del 28 de septiembre pues ahora se señalaban, visibilizaban y cuestionaban las acciones del Estado por apoyar a los grupos antiderechos y el uso indebido de los recursos humanos, materiales y financieros de las dependencias para ese fin.

La lucha seguía firme y se trató de incidir en todos los espacios, por lo que en el marco de la XI Semana del Derecho y la Seguridad Pública de la Universidad de Quintana Roo, la División de Ciencias Sociales y Económico Administrativas, a través del Cuerpo Académico de Estudios Multidisciplinarios en Derechos Humanos, efectuó el foro Hacia una Educación Sexual Integral, el cual fue impartido por la maestra Diana Ibarra Villarreal de la organización Planned Parenthood Global, el día 28 de noviembre de 2018, en el Aula Magna II de la Universidad de Quintana Roo. El foro buscó generar conciencia sobre lo que implica la educación integral de la sexualidad (ESI), por medio de la exposición y análisis, para comprender la relación de la ESI con los derechos sexuales y los derechos reproductivos. 
Para el mes de diciembre de 2018, la colectiva Marea Verde Quintana Roo pidió a la CEDHQROO que solicitara la ampliación de la alerta de violencia de género contra las mujeres (AVGM), ahora por agravio comparado en virtud de la violación de los derechos sexuales y reproductivos de las mujeres en el estado en comparación con las mujeres de la Ciudad de México, las cuales pueden acceder a la interrupción voluntaria del embarazo (IVE) de manera segura, legal y gratuita. La solicitud fue admitida y acumulada al procedimiento del mecanismo de la AVGM el 17 de enero de 2020, vigente en los municipios de Felipe Carrillo Puerto y Othón P. Blanco - municipio en el que se encuentra la cabecera del estado- (Maldonado, 2020).

\section{Quintana Roo y la lucha feminista en el 2019}

Las actividades continuaron en diversas partes de la entidad; se realizaron marchas y concentraciones en fechas como el 8 de marzo de 2019, cuando, en el marco del Día Internacional de la Mujer, se efectuó en la ciudad de Chetumal una rodada que finalizó con el desarrollo de actividades artísticas

y culturales para concientizar sobre los derechos sexuales y reproductivos de las mujeres, dado que limitar nuestro derecho a decidir es una forma de violencia que el Estado permite.

La iniciativa ciudadana a favor de la despenalización del aborto presentada por la colectiva Marea Verde Quintana Roo fue leída en el Pleno del Congreso del Estado de Quintana Roo, estando en ejercicio la XV Legislatura, el día 13 de marzo de 2019 (XV Legislatura, 2019) y fue pasada a discusión a la Comisión de Puntos Constitucionales, a la Comisión de Puntos Legislativos y Técnica Parlamentaria y a la Comisión de Justicia.

Sin embargo, las posturas antiderechos desde el mismo Estado seguían latentes. El 25 de marzo de 2019, se evidenció - a través de la página de Facebook de Marea Verde Quintana Roo- la posición antiderechos del Instituto Estatal para la Educación de Jóvenes y Adultos (IEEA), el cual se atrevió a señalar en su página oficial de Facebook que ese día se celebraba el Día del Niño por Nacer; éste fue el texto compartido por el IEEA: "Sin vida, no hay derechos humanos; sin ellos, no hay libertad. El derecho de la vida no es una cuestión de ideología ni religión, sino una consecuencia lógica de la naturaleza humana. \#FAMILIAIEEA, \#VIDA, \#DILESIALAVIDA, \#DÍADELNIÑO POR NACER". En ese sentido, se señaló en la página de la colectiva Marea Verde Quintana Roo lo siguiente: 
Intolerable que instituciones del Estado emitan esta serie de mensajes cuando la Corte Interamericana de Derechos Humanos ha establecido que "no es factible sostener que un embrión sea titular y ejerza los derechos consagrados en cada uno de dichos artículos". En este orden de ideas, dicha Corte estableció "[...] que la interpretación histórica y sistemática de los antecedentes existentes en el Sistema Interamericano, confirma que no es procedente otorgar el estatus de persona al embrión". (Marea Verde Quintana Roo, 2019c)

La publicación fue eliminada de la página del IEEA a las dos horas de haber sido subida, pero demuestra la necesidad de estar alertas del contenido que las instituciones oficiales comparten, así como la urgencia de la formación basada en derechos humanos que las dependencias del gobierno deben recibir para evitar anteponer sus estereotipos y prejuicios a la actividad que realizan.

El 29 de abril de 2019, se ingresó un escrito solicitando al Congreso, entre otras cosas, incorporar a la discusión del tema sobre la interrupción legal del embarazo (ILE) la iniciativa presentada el 7 de abril de 2017 por Carlos Manuel Joaquín González, gobernador del estado de Quintana Roo, en la que se preveía la modificación del Código Penal del estado para incluir, entre otros apartados, la despenalización del aborto hasta antes de los noventa días de gestación; también se pidió que fuera pasada al Pleno y a las comisiones, adjuntando al oficio la referida iniciativa con el acuse de recibido, misma que fuera presentada por el Ejecutivo estatal como parte del supuesto cumplimiento a las recomendaciones efectuadas por el Grupo de Trabajo conformado para estudiar la Solicitud de Alerta de Violencia de Género contra las Mujeres en los municipios de Benito Juárez, Cozumel, Isla Mujeres, Lázaro Cárdenas y Solidaridad en el estado de Quintana Roo.

En ese mismo escrito, se solicitó desestimar la iniciativa presentada por la diputada Sonia López Cardiel, presidenta de la Comisión de Salud y Asistencia Social de la XV Legislatura, por la cual se pretendían reformar diversas disposiciones contenidas en el Código Penal para el Estado Libre y Soberano de Quintana Roo, así como en la Ley de Salud del Estado de Quintana Roo. Se realizó un análisis lógico jurídico sobre los puntos de ésta que violentaban derechos humanos.

Se dieron varias entrevistas sobre el tema, lo que originó que se señalara a dicha exlegisladora y a su iniciativa como violentadora de derechos 
humanos, sobre todo porque solicitaba la esterilización forzada cuando una mujer se realizara una IVE por segunda vez, lo que llevó a posicionar el tema a nivel nacional. Una de las notas señalaba lo siguiente:

La diputada del estado mexicano Quintana Roo, Sonia López Cardiel de Morena, presentó un proyecto de ley que pretendía esterilizar a las mujeres que decidan abortar por segunda vez. La iniciativa fue rechazada por los políticos y el Consejo Consultivo de la Comisión Estatal de los Derechos Humanos la condenó enfáticamente. Al mismo tiempo, los distintos colectivos que trabajan por el derecho de la mujer a decidir sobre su propio cuerpo criticaron fuertemente a la legisladora. (Radio Mitre, 2019)

En otra se exponía la siguiente información:

La iniciativa de ley promovida por la diputada independiente en Quintana Roo, Sonia López Cardiel, para esterilizar a las mujeres que decidan abortar por segunda ocasión, fue rechazada por el Consejo Consultivo de la Comisión Estatal de los Derechos Humanos (CEDHQROO) y condenada por colectivos por el derecho a decidir en la entidad, quienes exigieron frenar, con carácter de urgente, la propuesta de la legisladora.

"Se trata de una medida punitiva y discriminatoria que refleja prejuicios y estereotipos de género, ya que se castigaría la mujer por abortar, y de manera específica, a las mujeres que viven vulneradas y empobrecidas, sin tomar en cuenta las distintas situaciones que viven las mujeres en las que el aborto se volvería una opción", afirmó el organismo, al exhortar a la legisladora a reconsiderar su propuesta. (Varillas, 2019c)

De igual manera, dado que casi nadie sabía de la iniciativa que el gobernador había presentado ante el Congreso del estado en abril de 2017, surgieron diversas notas que señalaban el hecho, especialmente porque su llegada al poder se dio a través de la coalición de los partidos PAN-PRD, lo que puso el tema nuevamente en la mesa de discusión. Ésta es una de las notas: 
Durante la XV Legislatura se presentaron al menos tres iniciativas de ley para despenalizar el aborto o aumentar las causales para permitir la interrupción segura del embarazo.

Una de esas iniciativas fue presentada por el gobernador, Carlos Joaquín González, el siete de abril de 2017, en respuesta a la declaratoria de la Alerta de Violencia de Género (AVG), decretada en ese año.

Esa iniciativa buscaba reformar, derogar y adicionar normativas del Código Penal, a favor de las mujeres, entre éstas, derogar los artículos 93 y 96 sobre la sanción del aborto y la modificación del artículo 94 y 97 que propone despenalizarlo.

De acuerdo con organizaciones civiles como Marea Verde-Quintana Roo y Derechos Autonomías y Sexualidades (DAS), la iniciativa, "extrañamente", "desapareció" o "se perdió", pese a que se cuenta con evidencias oficiales de que fue entregada, recibida y sellada por la Oficialía de Partes del Congreso.

En 2018 la segunda iniciativa para despenalizar el aborto en la entidad, fue presentada por Marea Verde a través de la Ley de Participación Ciudadana y fue estancada en comisiones.

Busca modificar el artículo 13 de la Constitución del estado; derogar el artículo 96, reformar los artículos 92, 93 y 97 del Código Penal estatal e incluye adicionar un capítulo sexto TER, sobre la interrupción legal del embarazo a la Ley de Salud.

La tercera iniciativa "congelada" fue impulsada el 13 de marzo pasado, por la entonces diputada, Sonia López, quien propone esterilizar a las mujeres que decidan abortar por segunda vez, castigar a la pareja de la mujer que decide interrumpir su embarazo y agregar una quinta causal económica a las cuatro ya existentes para permitir el aborto.

Tocará al nuevo Congreso entrarle de nuevo a discutir el tema, con responsabilidad, sin matices religiosos, ni morales; a la luz de la Ciencia y la laicidad y recordando que no legislan para defender sus creencias personales, sino para garantizar derechos bajo el principio pro persona. (Varillas, 2019a)

El 30 de mayo de 2019, integrantes de la colectiva Marea Verde Quintana Roo ingresaron un escrito en el que solicitaban al gobernador del es- 
tado que, en el uso de las facultades que le confiere el artículo 105, apartado A, fracción III de la Constitución Política del Estado Libre y Soberano de Quintana Roo, iniciara la acción por omisión legislativa en contra del Congreso del Estado de Quintana Roo, en virtud de no haber sometido a discusión del Pleno la iniciativa presentada por él mismo el 7 de abril de 2017, en la que preveía la modificación del Código Penal del estado, adjuntando la referida iniciativa con el acuse de recibido. La noticia fue difundida en algunos medios:

Reiteraron el interés del colectivo por el que dicha iniciativa sea discutida, en virtud que la aprobación de la reforma que propone el ejecutivo es en beneficio de los derechos sexuales y reproductivos de las mujeres en el estado y, dado, que en ella señala que todas las autoridades, en el ámbito de sus competencias, tienen la obligación de promover, respetar, proteger y garantizar los derechos humanos de conformidad con los principios de universalidad, interdependencia, indivisibilidad y progresividad, al proponer la derogación de los artículos 93 y 96 que sancionan actualmente a la mujer que voluntariamente se someta al aborto, y se modifica el artículo 94 y 97 para despenalizar el delito de aborto, dejando únicamente supuestos jurídicos en que será sancionado el delito, para limitar este derecho a la interrupción del embarazo a no más de 90 días de gestación del producto o bien, cuando sea en contra de la voluntad de la mujer, por coacción o amenazas y, en su caso, por negligencia o culpa de las y los profesionales de la salud. (Briceño, 2019)

Ese mismo día, 30 de mayo de 2019, se presentó en la Oficialía de Partes del Despacho del Gobernador del Estado un escrito en el que se informaba que se había tenido conocimiento sobre la negativa de las instituciones de salud públicas a realizar las IVE así como a prescribir la profilaxis contra VIH/SIDA en casos de violación, condicionando ambas a la presentación de la denuncia ante la Fiscalía General del Estado. El escrito contenía una argumentación jurídica de por qué esa condicionante es violatoria de los derechos humanos.

Como consecuencia de estas acciones, el 31 de mayo de 2019, rescindieron laboralmente a una integrante de la colectiva sin razón fundada ni motivada, de donde se deduce que fue una represalia y un acto de discri- 
minación por el hecho de ser mujer, por ser activista defensora de los derechos humanos -específicamente de los derechos sexuales y reproductivos de las mujeres en el estado- y por la molestia que las acciones de la colectiva generaron al Gobierno.

El 11 de junio de 2019, gracias al apoyo de mujeres y colectivas feministas, al respaldo y alianzas con feministas en el Congreso de la Unión y de diversas colectivas y organizaciones a favor de los derechos humanos, se logró la reinstalación enviando un mensaje claro y contundente: ninguna integrante de cualquier colectiva que esté a favor del derecho a decidir de las mujeres en Quintana Roo, podría ser vulnerada en sus derechos laborales por posicionarse a favor de la IVE. Al respecto se dieron algunas notas, entre ellas la siguiente:

La maestra [...] fue reinstalada como docente investigadora en la Universidad de Quintana Roo (UQROO) luego de ser despedida en días pasados, "resultado de un diálogo en el que se ponderó la legalidad y el respeto a los derechos humanos", informó mediante un comunicado la organización Marea Verde Quintana Roo.

El pasado 31 de mayo la docente fue notificada mediante un oficio firmado por el rector de la universidad, Ángel Rivero Palomo, sobre su cese en el cargo como Profesora Investigadora de Carrera Asociado A.

"Toda vez que ya no es necesaria la subsistencia de continuar contando con sus servicios, con la presente fecha 31 de mayo de 2019, se le notifica la terminación definitiva de su contrato por tiempo determinado como Profesora Investigadora de Carrera Asociado A, al servicio de la Universidad de Quintana Roo", decía el escrito entregado a la activista de Marea Verde.

Luego de este oficio, que no recibió formalmente, la docente de la UQROO adscrita al Departamento de Ciencias Jurídicas de la División de Ciencias Sociales y Económico Administrativa denunció un "intento de pretender silenciar a quienes defendemos los derechos humanos en el estado".

Además promovió una queja ante la Comisión de los Derechos $\mathrm{Hu}-$ manos del Estado de Quintana Roo (CEDHQROO) por posibles violaciones a sus derechos humanos y posteriormente inició un plantón e000204. https://doi.org/10.48102/if.2022.v2.n1.204 Licencia Pública Internacional - CC BY-NC-ND 4.0 
a las afueras de Casa de Gobierno para solicitar la intervención del Ejecutivo del estado.

La UQROO informó mediante un breve comunicado que el despido [...] había obedecido a temas estrictamente universitarios ratificando que en la determinación no habían intervenido en forma alguna instancias externas a esa casa de estudios.

"Agradecemos a todas las personas, compañeras feministas, alumnos y alumnas, egresadas y egresados, colectivos y organizaciones que mostraron su preocupación y apoyo al colectivo y a la doctora [...]. Hemos tejido una maravillosa red reforzada con alianzas que nos impulsan a seguir trabajando", comunicó Marea Verde. (Maldonado, 2019)

Del 12 al 14 de julio de 2019, Marea Verde Quintana Roo, en coordinación con Grupo de Información en Reproducción Elegida (GIRE), el Programa de Jóvenes por los Derechos Sexuales y Reproductivos (REDefine Quintana Roo), así como con el apoyo de las organizaciones Fondo María, el Instituto de Liderazgo Simone de Beauvoir (ILSB), Balance Fondo María y Fondo Semillas, efectuó en Chetumal el 3.er Encuentro Regional "Hablemos de Aborto" (Varillas, 2019b), al que asistieron compañeras de seis estados de la región sur-sureste de la República mexicana, lo que permitió afianzar redes aún más fuertes, además de aprender técnicas y herramientas diversas para la lucha (Marea Verde Quintana Roo, 2019b).

Antes del encuentro, el 11 de julio de 2019, se efectuó una conferencia de prensa en la que se posicionó la necesidad de respetar los derechos sexuales y reproductivos de las mujeres en el estado. El evento fue difundido por diversos medios de comunicación:

La asociación civil Marea Verde dio a conocer que durante este fin de semana se llevará a cabo el encuentro regional "Hablemos de aborto", en el cual participarán diversas organizaciones en pro de la legalización del aborto de seis estados de la República, Quintana Roo, Yucatán, Campeche, Tabasco, Chiapas y Veracruz.

En conferencia de prensa el Movimiento de mujeres "Marea Verde" dio a conocer que durante este fin de semana se llevará a cabo un encuentro regional en el cual se unirán varias organizaciones en pro de 
legalizar el aborto, ya que a su parecer en muchos estados entre ellos Quintana Roo, no se garantiza la posibilidad de poder interrumpir el embarazo ni en las primeras semanas.

Mencionaron que esto es "una deuda pendiente" del estado hacia las mujeres, ya que Quintana Roo se ubica en los primeros lugares en solicitar este proceso en el estado de México donde es legal siendo más de 126 mujeres las que han optado por esta práctica, sin embargo, no todas las mujeres que preferirían recurrir a esto cuentan con las posibilidades económicas. (Montiel, 2019)

El 24 de septiembre de 2019 (a un año de haber presentado la iniciativa ciudadana), en virtud del cambio de las y los integrantes de la Legislatura del Estado, se presentó una solicitud para que, en esta nueva XVI Legislatura, la iniciativa - que había pasado a Pleno y comisiones el 13 de marzo de 2019- fuera discutida y, en su caso, aprobada para lograr un avance en el reconocimiento, respeto y garantía de los derechos sexuales y reproductivos de las mujeres en México.

El 25 de septiembre de 2019, las emociones y el corazón se pintaron de verde al saber que la Legislatura del Estado de Oaxaca había aprobado la despenalización del aborto hasta la decimosegunda semana de gestación, lo que sin duda incrementó el ánimo de las quintanarroenses para seguir insistiendo en lograr igualdad de derechos como las mujeres de la Ciudad de México y ahora Oaxaca.

Con una fuerte convicción de la causa, el 28 de septiembre de 2019, se efectuó la segunda marcha en el marco del Día de Acción Global por el Acceso al Aborto Legal y Seguro, conocido también como el Día por la Despenalización y Legalización del Aborto. Se registró una mayor afluencia de personas y eso sin duda seguía poniendo el tema en la agenda.

El 22 de octubre de 2019, se realizó el Foro de Discusión: La interrupción legal del embarazo en Quintana Roo; un tema en la agenda legislativa nacional, en el marco de la XII Semana Cultural del Derecho y la Seguridad Pública en la Universidad de Quintana Roo. Con ello se seguía incidiendo en todos los espacios para establecer la necesidad y urgencia de dejar de criminalizar el derecho a decidir de las mujeres en la entidad y en el país (Marea Verde Quintana Roo, 2019a).

El 25 de noviembre de 2019, las mujeres salieron de nuevo a las calles para exigir un alto a la violencia contra las mujeres, incluyendo la violación 
a los derechos sexuales y reproductivos ejercida por la criminalización del aborto; exigieron también acciones reales y concretas, más allá de sólo ponerse un lazo naranja y dar discursos que no impactan en la realidad que viven las mujeres día a día.

\section{Un año determinante para \\ la lucha en Quintana Roo}

El 8 de marzo de 2020, mujeres de diversas colectivas y organizaciones de la sociedad civil, así como mujeres que nunca habían asistido a una marcha feminista, decidieron salir a las calles y unir sus voces para visibilizar la gravedad de la situación frente a la criminalización del derecho a decidir y el incremento de la violencia contra las mujeres.

Como se observa, para lograr avances, incluida la armonización legislativa con perspectiva de género, se habían efectuado desde hace más de tres años programas de atención, defensa, acompañamiento y orientación a las víctimas de violencia de género, mesas de trabajo con las dependencias estatales, elaboración de pliegos petitorios e iniciativas legislativas y programáticas, marchas, concentraciones, pronunciamientos públicos, conversatorios, foros, visitas personalizadas, programas de capacitación a servidoras y servidores públicos. Además, se había insistido en que se cumplieran las medidas establecidas en la Declaratoria de Alerta de Violencia de Género contra las Mujeres (en adelante Declaratoria de AVGM), señalando las omisiones y obstáculos para un verdadero y efectivo acceso a la seguridad y justicia.

Marzo de 2020 fue un mes especialmente singular para la lucha; podemos mencionar varias razones:

- El 7 de marzo se efectuó el primer evento en conjunto con la colectiva Foráneas Seguras, que trabaja en la cabecera de José María Morelos, uno de los municipios mayas del estado de Quintana Roo. Se efectuaron talleres y carteles, se llevó a cabo la primera marcha por la despenalización del aborto en dicha cabecera y se pintó un mural que alude al movimiento (Marea Verde Quintana Roo, 2020b).

- El 8 de marzo se efectuó la marcha por el Día Internacional de la Mujer, a la que cada vez concurren más y más mujeres para gritar y exigir que puedan decidir sobre el primer territorio que es su cuerpo. 
- Del martes 10 al viernes 13 de marzo de 2020, se efectuó el Primer Parlamento de Mujeres, organizado por la XVI Legislatura del Congreso del Estado de Quintana Roo, autodenominada la "Legislatura de la Paridad". Participaron integrantes de colectivas feministas, quienes llevaron a la tribuna la necesidad de implementar la igualdad de género en la agenda legislativa (Congresoqroo, 2020d), de lograr la paridad efectiva (Congresoqroo, 2020a), de crear políticas institucionales que sancionen a los funcionarios y servidores públicos que obstaculicen la atención a las víctimas de violencia en todos los ámbitos (Congresoqroo, 2020b), así como de despenalizar el aborto como política de salud pública y reproductiva de las mujeres en la entidad (Congresoqroo, 2020c).

Sin embargo, por las mismas fechas, se decretó la existencia de la pandemia mundial por el virus SARS-CoV-2 (que produce la enfermedad COVID-19), lo cual puso a toda la población bajo alerta y, a su vez, trajo consecuencias en perjuicio de los derechos sexuales y reproductivos de las mujeres dado que, ante la recomendación de quedarse en casa, una gran mayoría de las mujeres y niñas quedaron expuestas a convivir con sus agresores y a vivir relaciones sexuales forzadas y embarazos no deseados. Al respecto, la Red Nacional de Refugios señaló:

La pandemia de COVID-19 también ha acentuado la violencia de género en México, pues a cuatro meses del confinamiento, la violencia contra mujeres, niñas, niños y adolescentes se ha incrementado $81 \%$, respecto al mismo periodo de 2019.

Así lo advirtió la Red Nacional de Refugios, AC. (RNR), quien dijo haber atendido a 14 mil 599 mujeres con sus hijas e hijos, entre marzo y junio.

[‥] (Animal Político, 2020)

En su informe mensual, la red insistió en que la violencia machista está afectando gravemente a la infancia, pues $46 \%$ de las hijas e hijos de las mujeres que pidieron apoyo fueron víctimas de violencias en sus casas durante el confinamiento; el 8\% (casi 500 menores de edad) fueron víctimas de violencia sexual mientras se quedaban en casa, "lo que nuevamente 
evidencia que no todas las familias mexicanas son espacios de fraternidad", refirió. (Animal Político, 2020)

Al ponderarse la atención de las personas contagiadas por el virus, los métodos anticonceptivos - que de por sí no eran ministrados adecuadamente en los hospitales y centros de salud públicos con la debida continuidadsimplemente dejaron de proporcionarse: "Al menos 12 millones de mujeres han sufrido la interrupción de servicios de planificación familiar debido a la pandemia de COVID-19, informó el jueves el Fondo de Población de las Naciones Unidas (UNFPA). Debido a la situación, 1.4 millones de mujeres han tenido embarazos no deseados, indica el reporte" (López Pérez, 2021).

Esa omisión del Estado provocó que las colectivas y organizaciones dedicadas a dar acompañamientos tuvieran que crear nuevas alternativas para proporcionar información y guía sobre el proceso de interrupción del embarazo desde sus casas a muchas mujeres y adolescentes que tenían que pasar el proceso solas, aunque hubiera otras personas en sus hogares -entre ellas, sus propios agresores-.

A través de las páginas de las colectivas, se generaron contenidos más claros y directos sobre la opción de la IVE y la obligación del Estado de efectuar la ILE en casos de violación en aplicación y cumplimiento de la NOM-046-SSA2-2005, que establece los criterios para la prevención y atención de la violencia familiar, sexual y contra las mujeres.

En ese contexto, el 28 de septiembre de 2020, pese a la pandemia y con todas las medidas de cuidado y protección, se realizó la tercera marcha por el aborto seguro, legal y gratuito en Chetumal, convocada por la colectiva Marea Verde Quintana Roo. Se exigió al Congreso del estado que trabajara a favor de los derechos sexuales y reproductivos de las mujeres puesto que los diputados y diputadas simplemente se negaban a discutir las tres iniciativas que ya se habían presentado y las dos que se habían sumado ese año:

- La del 9 de marzo de 2020, presentada por la diputada Ana Ellamin Pamplona Ramírez en el marco del Día Internacional de la Mujer, la cual fuera turnada a la Comisión de Puntos Constitucionales, la Comisión de Salud, la Comisión de Igualdad de Género, la Comisión de Derechos Humanos y a la Comisión de Justicia (Macronews, 2020).

- La del 2 de septiembre de 2020, presentada por el diputado José Luis Guillén en respuesta al exhorto ciudadano enviado a la Comisión Per- 
manente; turnada a la Comisión de Justicia y a la Comisión de Salud (MarcrixNoticias, 2020).

El 9 de noviembre de 2020, como protesta frente a los feminicidios recurrentes en el estado y específicamente al de Bianca Alejandrina Lorenzana Alvarado, conocida como Alexis, ${ }^{3}$ se organizaron manifestaciones en las fiscalías de diversos municipios de Quintana Roo para exigir justicia para las mujeres víctimas de violencia feminicida.

En la ciudad de Cancún, las y los manifestantes, incluidas algunas de las integrantes de la Red Feminista Quintanarroense de la que es parte Marea Verde Quintana Roo, decidieron protestar frente al Palacio Municipal de Benito Juárez. La protesta fue reprimida a balazos: tres personas resultaron heridas por impactos directos de bala (una mujer manifestante, una mujer periodista y un hombre periodista); hubo también un número indeterminado de personas lesionadas por golpes y ocho personas detenidas arbitrariamente (siete mujeres y un hombre) que esa misma noche fueron liberadas ante la palmaria ilegalidad de su detención.

En la protesta estaban presentes niñas, niños y adolescentes, así como personas adultas mayores, cuya vida e integridad estuvieron en riesgo debido a la actuación de la policía. De acuerdo con la información oficial, en el operativo para reprimir la protesta participaron al menos setenta y ocho agentes de policía, lo cual descarta que haya sido un hecho aislado.

A pesar de que el gobierno del estado anunció una investigación de los hechos, hasta la fecha no existe información sobre las responsabilidades en la cadena de mando. Es de destacar que, aunque algunas autoridades mencionaron que durante la protesta se produjeron hechos vandálicos, éstos fueron cometidos principalmente por hombres según testigos y las propias autoridades; sin embargo tanto las heridas por arma de fuego como las detenidas fueron casi en su totalidad mujeres, lo cual muestra la existencia de un fuerte componente de discriminación por

3 Alexis fue reportada como desaparecida el 7 de noviembre de 2020; su cuerpo fue encontrado al día siguiente. La Fiscalía de Quintana Roo emitió un comunicado para informar que "el cuerpo de una mujer de 20 años, plenamente identificada por sus familiares con las siglas B.A.L.A., había sido localizado ‘sin vida y con claras huellas de violencia' [...] en el municipio de Benito Juárez" e inició una carpeta de investigación por el feminicidio (El Universal, 2020). 
motivos de género en el actuar de la policía. Este hecho sienta precedente como uno de los eventos más violentos de represión a la protesta por parte del Estado en los últimos años.

Ante estos hechos, el 16 de noviembre de 2020, la RFQ presentó un pliego de peticiones a los tres poderes del estado en el que, de manera enunciativa más no limitativa, se señalaban cincuenta y cuatro puntos para lograr cambios estructurales en favor de los derechos de las mujeres y niñas. Entre los puntos planteados, hay diez acciones legislativas concretas, como la urgente discusión y el análisis de las iniciativas en torno a la despenalización del aborto. La insistencia nunca pretendió orientar el voto de las legisladoras y legisladores, sino garantizar que efectivamente se discutieran las iniciativas presentadas sobre derechos sexuales y reproductivos y que no quedaran olvidadas como si los derechos de las mujeres y niñas no existieran (Varillas, 2020).

Tras la sistemática omisión y negativa de los y las legisladoras integrantes de las comisiones a las que fueron turnadas las iniciativas a favor de la despenalización del aborto, la marea verde en Quintana Roo - conformada por las colectivas y organizaciones a favor del derecho a decidir incorporadas a la RFQ- tomó la decisión de realizar acciones directas para visibilizar la causa y la lucha.

\section{5 de noviembre de 2020}

Desde la RFQ, con motivo del Día Internacional de la Eliminación de la Violencia contra la Mujer, se organizaron movilizaciones pacíficas en varios municipios del estado. A la convocatoria se le denominó "Digna Rabia". Una nota resumió así las actividades planeadas: "Durante la marcha denominada 'Digna Rabia' al que se unen colectivas feministas de Felipe Carrillo Puerto, se realizará actividades culturales, lecturas de posicionamientos, colocación de zapatillas rojas y galerías de mujeres desaparecidas" (Chán, 2020).

En Chetumal, la capital del estado, Marea Verde Quintana Roo convocó a una concentración; tras concluir las actividades culturales planeadas, se leyó un pronunciamiento en el que se informó que se instalaría un plantón en la plazoleta del Congreso del estado desde ese día (25 de noviembre) (Maldonado et al., 2020). El pronunciamiento, que se leyó de manera simultánea en los municipios en donde hubo marchas o concentraciones, expresaba lo siguiente: 
Un día tuvimos un sueño muy bonito, soñamos que podíamos estar en casa y nadie nos iba a violentar; un día soñamos que podíamos salir a las calles y nadie nos iba a lastimar ni agredir; un día soñamos que íbamos a decidir sobre nuestras cuerpas, sobre nuestros territorios y sobre nuestras vidas.

Hermanas nuestras, ese sueño se construye en este instante con todas ustedes aquí reunidas para protestar por los feminicidios, las desapariciones de mujeres y niñas; ese sueño se construye porque estamos acabando con todos esos tipos de violencia que ejercen en nuestra contra.

Hoy salimos a las calles a gritar, llorar y seguir luchando en el marco del Día Internacional para la Eliminación de la Violencia contra las Mujeres, porque estamos en un Quintana Roo feminicida, porque vivimos en un México feminicida y hoy llenamos las calles y los espacios públicos porque estamos luchando por nuestras vidas, porque ¡nos queremos vivas!

Desde las entrañas gritamos alto al feminicidio, ni una menos; vivas nos queremos. Estamos construyendo una vida donde el derecho a decidir sobre nuestras cuerpas no sea cuestionado bajo ningún dogma; una vida donde sea cuestionable la violación y no el aborto, donde se respete la laicidad del Estado.

Hoy levantamos la voz rabiosa porque queremos una vida libre de violencia. Estamos en un momento de emergencia; los enemigos son fuertes, son muchos, son machos y están por todas partes. Necesitamos un pacto entre mujeres, nos necesitamos juntas. Debemos seguir organizándonos como mujeres, seguir en las calles. Estamos en tiempos de guerra y, en estos tiempos de guerra, juntas somos más fuertes.

El sistema patriarcal y sus instituciones patriarcales está utilizando sus mecanismos de impunidad, de corrupción para reprimir con violencia a las mujeres que nos movilizamos, para decirnos que no podremos contras sus múltiples violencias que nos matan, que nos criminalizan y señalan como las culpables de sus violencias sexuales y feminicidas; pero nosotras sabemos que los estamos tirando y por eso nos temen, por eso hoy nos ponen estas vallas, por eso hoy nos mandan a sus policías listos para defender sus edificios, sus símbolos de poder, iporque nosotras estamos cansadas y porque nuestro sentido 
común de resistencia es defender nuestras cuerpas, la tierra y nuestras vidas!

Este 25 de noviembre expresamos nuestra indignación y rabia porque ningún tipo de violencia puede seguir justificándose.

- Nos indigna la saña, crueldad y misoginia contra los cuerpos de las mujeres víctimas de femicidios y violencia sexual; por las que son explotadas con fines sexuales, por las que ahora están desaparecidas sin poder abrazar a sus amigas y familias.

- Nos enojan los actos de misoginia extrema, violencia de género dentro de sus instituciones que les da impunidad a esos violentadores que nos someten, nos controlan, nos golpean, nos violan o asesinan y que, cuando denunciamos, la autoridad es totalmente cómplice e ineficiente.

- Nos indigna que ninguna mujer pueda salir tranquila a las calles sin ser víctima de acoso callejero.

- Nos indignan los linchamientos cibernéticos de quienes siguen culpando a las mujeres que denuncian o se rebelan a seguir tolerando la violencia.

- Nos indigna el morbo, la nota roja, amarillista en el abordaje de los medios de comunicación que siguen normalizando las violencias y que no respetan los derechos y dignidad de las mujeres.

- Nos indigna la publicidad comercial que sigue cosificando el cuerpo de las mujeres y denigrando su condición de humanas.

- Nos indigna que las mujeres no podamos decidir sobre nuestro cuerpo y la reproducción, con la imposición de embarazos por violación, no planificados o que ponen en riesgo nuestra salud y nuestra vida.

- Nos indigna que mujeres, adolescentes y niñas sigan siendo utilizadas y violentadas en todas y cada una de sus instituciones, como la familia, las escuelas, los centros laborales, los templos e iglesias; nos violentan en los juzgados y ministerios públicos con su impunidad; en sus congresos que criminalizan nuestros cuerpos, que protegen a los agresores con impunidad y misoginia; no tenemos un espacio donde se nos garantice una vida libre de violencia.

Por eso es que hoy venimos a exigir: 
A nivel estado en todas las instancias de prevención, atención, investigación y sanción de la violencia de género: el cumplimiento de todos y cada uno de los 54 puntos del pliego petitorio de la Red Feminista Quintanarroense entregada al gobernador el pasado 16 de noviembre, donde dicho cumplimiento conlleve la inclusión real y eficiente de las colectivas y organizaciones dentro de las mesas de trabajo.

La despenalización del aborto en Quintana Roo; dado que llevamos años exigiendo que dejen de criminalizar nuestros cuerpos y limitando nuestro derecho a decidir, exigimos al Congreso del Estado de Quintana Roo efectúen la discusión y votación de las iniciativas para la reforma a la normativa estatal a efecto de despenalizar el aborto hasta la décimo segunda semana.

Quintana Roo presenta una situación única dentro de todos los estados del país. Se han presentado para proceso legislativo cuatro iniciativas que contemplan la despenalización del aborto en los últimos tres años. Y aunque tres de ellas han sido turnadas a comisiones, éstas no han sido discutidas; por el contrario, han sido ignoradas, desaparecidas e incluso tergiversadas en total desapego al principio de progresividad de los derechos humanos y sin incorporar la perspectiva de género.

La primera el 7 de abril de 2017, presentada por el C. P. Carlos Manuel Joaquín González, gobernador del estado, como parte de las evidencias de cumplimiento en lo que respecta a la armonización legislativa recomendada en el informe del Grupo de Trabajo conformado para estudiar la Solicitud de Alerta de Violencia de Género contra las Mujeres en los Municipios de Benito Juárez, Cozumel, Isla Mujeres, Lázaro Cárdenas y Solidaridad en el Estado de Quintana Roo, la cual hasta el momento no ha sido leída en Pleno ni pasada a Comisiones.

La segunda el 24 de septiembre de 2018, iniciativa ciudadana presentada por la colectiva Marea Verde Quintana Roo. Turnada a la Comisión de Puntos Constitucionales; Comisión de Puntos Legislativos y Técnica Parlamentaria y a la Comisión de Justicia.

La tercera el 9 de marzo de 2020, presentada por la diputada Ana Ellamín Pamplona Ramírez, en el marco del Día Internacional de la Mujer. Turnada a la Comisión de Puntos Constitucionales; Comisión de Salud, Comisión de Igualdad de Género, Comisión de Derechos Humanos y a la Comisión de Justicia. 
La cuarta el 2 de septiembre de 2020, presentada por el diputado José Luis Guillén en respuesta al exhorto ciudadano enviado a la Comisión Permanente. Y turnado a la Comisión de Justicia y a la Comisión de Salud.

Hemos decidido no esperar más. Después de presentar iniciativas, efectuar marchas, pronunciamientos, concentraciones, foros de discusión, acercamientos a diputados y diputadas, presentación de pliego de peticiones y demás actos, estamos hartas de excusas, pretextos, simulaciones y discursos manifestando estar a favor de los derechos de las mujeres y en contra de la violencia contra la mujer, cuando en realidad no efectúan actos que demuestren congruencia.

A las víctimas de todos los tipos de violencia, queremos expresarles que no están solas, que las feministas seguiremos elevando nuestras voces y denunciando, acompañando, buscando justicia y luchando por la sanción legal y social de estos crímenes de odio, poder y lesa humanidad.

Saludamos y abrazamos la valentía de todas ustedes y de las que hoy luchan contra la depresión, contra los estereotipos, contra un mundo que nos quiere ver sumisas; nos reconocemos en nuestros aportes y acuerpamiento; saludamos nuestras sabidurías y rebeldías; desde nuestras cuerpas insumisas, seguimos acuerpadas, seguimos tejiendo siempre unidas, sin miedo porque nos lo quitaron; seguimos más fuertes, más aliadas.

Por último, hacemos un llamado a todas las mujeres quintanarroenses a realizar un plantón afuera del Congreso estatal en Chetumal, comenzando en este momento.

Desde la Red Feminista Quintanarroense hacemos un llamado a acuerparnos. El objetivo de este plantón es exigir que se aborden las iniciativas del pliego petitorio entregado al gobernador del estado de Quintana Roo, como también para reclamar la despenalización del aborto. Porque nosotras ya decidimos. El aborto debe despenalizarse y Quintana Roo debe ser el tercer estado de la nación en brindar ese derecho a las mujeres.

Pedimos estar atentas, a seguir denunciando públicamente junto a nosotras las amenazas, pero también la demanda de justicia por el respeto a la vida de las mujeres defensoras de la vida plural del planeta. 
¡Alerta, nos están matando!

¡Detengamos la violencia machista!

¡No más impunidad!

¡Tenemos derecho a vivir libres de violencia machista!

¡Ni una menos!

¡Tenemos derecho a la vida! (Marea Verde Quintana Roo, 2020a)

Así iniciaba el plantón que, dos días después, llevaría a la toma pacífica del Congreso del Estado de Quintana Roo, la cual se sostuvo durante noventa y cinco días, de los cuales cuarenta y seis se estuvo sin luz ni agua. A pesar de ello, la lucha se mantuvo firme en el objetivo: lograr la dictaminación y la votación del tema para así poder acceder a las vías jurisdiccionales para exigir se respete, garantice y proteja el derecho a decidir. Marea Verde Quintana Roo fue una colectiva que participó activamente en mantener el plantón y sostener la toma.

\section{Antimonumenta}

El 29 de noviembre de 2020, en el marco de la toma y como una de las acciones ya planeadas, se instaló en los jardines del Congreso del Estado de Quintana Roo una estructura elaborada a base de fibra de vidrio a la que se denominó "Antimonumenta"; contiene el símbolo del feminismo -de color morado- y el puño - de color verde- que representa la lucha por el aborto legal, seguro y gratuito. En uno de sus lados se observan, en letras mayúsculas, las consignas "Alto a la violencia contra las mujeres" -arriba, en el aro- y "iNi una más!" - abajo, en el travesaño- para exigir un alto a cualquier tipo o modalidad de violencia, especialmente la feminicida. En el otro lado de la Antimonumenta, en la cara que da hacia el Congreso, se lee la consigna "iNuestros derechos no son negociables!" -en el aro, en mayúsculas-, en alusión a la intención de las y los legisladores de seguir sometiendo a consulta nuestros derechos sexuales y reproductivos; en la parte de abajo, sobre el travesaño, se repite la consigna "iNi una menos!". Al pie de la Antimonumenta, se instaló una placa con los nombres de las mujeres y niñas cuyas vidas fueron arrebatadas por la violencia feminicida; esta placa se creó con la intención de que fuera reconocida como una reparación simbólica a las víctimas de feminicidio en el estado de Quintana Roo, lo cual fue una de las medidas de reparación señaladas en la Declaratoria de AVGM, emitida el 7 de julio de 2017: 
Determinar una medida de reparación simbólica para todas las mujeres que han sido víctimas de feminicidio en el Estado de Quintana Roo. Para la definición de la reparación simbólica se tomará en cuenta a las organizaciones de la sociedad civil y los familiares de las víctimas. (Comisión Nacional para Prevenir y Erradicar la Violencia Contra las Mujeres [CONAVIM], 2017, p. 5)

Es un símbolo de la lucha, de la resistencia, de la protesta, de la exigencia de la lucha feminista; una estructura que significa tanto y que pretende ser un recordatorio de esta generación de mujeres que se ha mantenido firme en la causa por disminuir y, en lo posible, erradicar todas las formas de violencia contra las mujeres, incluyendo la limitación del derecho a decidir, que es una de las principales consignas de la marea verde en el mundo.

La Antimonumenta fue dañada la madrugada del 11 de marzo de 2021. Según fotografías subidas por grupos antiderechos, fueron en una camioneta, se subieron a la banqueta de los jardines del Congreso y tuvieron que usar herramienta - cadenas- para arrancar la parte de arriba; no obstante, "nadie vio nada", ni siquiera las múltiples cámaras de vigilancia que el gobierno del estado presume haber adquirido, ni siquiera el personal de vigilancia de la XVI Legislatura que siempre estaba atento a todo lo que hacían las feministas durante la toma pacífica, y mucho menos los policías y patrullas que normalmente circulan en el área.

En un comunicado, la RFQ expresó lo siguiente:

Con mucho dolor y rabia el día de hoy encontramos nuestra ANTIMONUMENTA DESTRUIDA, la antimonumenta no sólo es una escultura, es un SÍMBOLO DE AUSENCIA, de ausencia de ley y de ausencia de ellas, las que nos faltan. ES UN SÍMBOLO DE LUCHA, QUE LLAMA A HACER MEMORIA COLECTIVA POR LAS MUJERES ASESINADAS Y A NO DEJAR QUE SUS NOMBRES SEAN OLVIDADOS, es una forma de acompañar a sus familias, quienes estuvieron presentes cuando la colocamos y a quienes les generó una forma de abrazar el recuerdo de ellas; hoy con coraje y amorosa rabia les decimos por CADA ANTIMONUMENTA QUE NOS TUMBEN LES PONDREMOS MUCHAS MAS!! (Voces Feministas, 2021) 
Otra nota señala el significado de la Antimonumenta y de su destrucción:

La "Antimonumenta", instalada por la Red Feminista Quintanarroense (RFQ) durante la toma pacífica del Congreso del estado en noviembre pasado, fue parcialmente destruida, lo que motivó la realización, hoy, de una protesta pacífica en Chetumal, durante [la cual] se colocaron flores y velas frente a la estructura que honra y visibiliza los nombres de las mujeres víctimas de feminicidio en el estado.

La pieza era la tercera en su tipo instalada en México y fue montada en el Sendero de la Igualdad, fuera del recinto legislativo, el 29 de noviembre del 2020, dos días después de la toma del Congreso en demanda de la dictaminación y votación en pleno de la despenalización del aborto hasta las 12 semanas de gestación.

La estructura de fibra de vidrio estaba conformada por una base de cemento, una losa con los nombres de mujeres asesinadas, una especie de cruz violeta con la leyenda "ni una más" y en la parte superior un puño verde, dentro de un anillo en el que se leía en letras blancas "Alto a la violencia contra las mujeres".

La pieza, sufragada con la cooperación monetaria de familiares que perdieron a sus hijas, madres o hermanas, así como de las propias defensoras de derechos humanos, fue "descabezada" y se arrojó pintura blanca sobre los nombres de las víctimas, entre la noche y la madrugada de hoy, en un acto calificado por las agrupaciones feministas como "un acto de odio" contra las manifestantes.

"Con mucho dolor y rabia el día de hoy encontramos nuestra Antimonumenta destruida. La Antimonumenta no sólo es una escultura, es un símbolo de ausencia, de ausencia de ley y de ausencia de ellas, las que nos faltan.

"Es un símbolo de lucha, que llama a hacer memoria colectiva por las mujeres asesinadas y a no dejar que sus nombres sean olvidados. Es una forma de acompañar a sus familias, quienes estuvieron presentes cuando la colocamos y a quienes les generó una forma de abrazar el recuerdo de ellas", reprocharon colectivas feministas.

Reunidas en torno a lo que quedó de la estructura - sólo la cruz violeta con la leyenda "ni una más"-, las defensoras de derechos humanos advirtieron que por cada Antimonumenta que se derribe, 
levantarán más, porque "no estamos dispuestas a que nos maten dos veces a nuestras asesinadas".

Uriel Ezqueda, una persona que en redes sociales se identifica como "provida", como se hacen llamar los grupos conservadores, subió fotos tomadas anoche, en donde se aprecia la parte superior de la Antimonumenta derrumbada sobre el piso y acompañó las imágenes como "héroes sin capa".

Al respecto, la Red subrayó que, si los responsables de la destrucción parcial de un símbolo para guardar la memoria de las víctimas piensan que con ello dañan a las feministas, se equivocan.

"Éste es un ataque a la memoria de nuestras hermanas asesinadas y sus familias, y eso no lo vamos a perdonar", advirtieron.

Al mostrar los pedazos de la circunferencia destruida, señalaron que así es la vida de las mujeres que son objeto de alguna o varias modalidades de la violencia de género, cuya cúspide es el feminicidio.

También responsabilizaron de lo sucedido al gobernador del estado, Carlos Joaquín González, a quien ubican como "cómplice pasivo", toda vez que, durante la última reunión que sostuvieron con él, se le solicitó el reconocimiento de la Antimonumenta como reparación simbólica y de reconocimiento a la memoria colectiva de las víctimas de feminicidio.

"Usted calló, usted omitió y usted está encubriendo a estas personas que hoy como vándalos, que ellos sí lo son, por la noche, pretendieron arrancar nuestra memoria".

"[...] Hoy también gritamos al Congreso del estado al negarse a cuidar esta memoria colectiva y el recuerdo y nombres de nuestras asesinadas", manifestaron, al señalar que, al igual que como sucedió cuando los murales plasmados sobre el exterior del Congreso, se negó el acceso a las grabaciones de las cámaras de seguridad, para ubicar a quienes les arrojaron pintura blanca, dañándolos.

Las activistas alertaron sobre "el odio loco" fomentado por agrupaciones religiosas, diputados y partidos políticos de ultraderecha y grupos conservadores, en contra del movimiento feminista.

También cuestionaron a las autoridades cómo van a cuidar a las mujeres, si ni siquiera pueden evitar que un monumento que honra a las víctimas de violencia feminicida sea respetado. (Varillas, 2021) 
Sin embargo, como el ave fénix que renace de sus cenizas, el 26 de junio de 2021, con el apoyo del sector empresarial de la ciudad de Chetumal y las aportaciones de las que integran la RFQ, se erigió de nuevo la Antimonumenta, ahora hecha de hierro, más fuerte y firme como la lucha.

La noche previa a la develación, se custodió la pieza y algunas feministas durmieron nuevamente a las afueras de la que ahora denominan "la Congresa"; al día siguiente, tras la ceremonia maya realizada por las hermanas de la colectiva Casa de la Mujer Indígena U Muk'iil Ko'olelo'ob María Uicab y de la Coordinadora de Mujeres Mayas de Quintana Roo, se hizo el pase de lista de las mujeres asesinadas a mano de la violencia feminicida.

El pronunciamiento que se leyó al develarla fue el siguiente:

En Quintana Roo nos asesinan, nos violentan y nos desaparecen sin el mínimo respeto a nuestras vidas y a nuestros derechos. Anulan nuestros sueños y proyectos de vida, se invalidan nuestras voces y se callan nuestras dolencias, nos amedrentan y nos niegan una vida digna.

Hoy las mujeres les hemos puesto un alto a esos que tratan de callarnos, a esos que tratan de amedrentarnos, a esos que impiden el acceso a la justicia a las miles de mujeres quintanarroenses que hoy claman por la vida de nuestras hermanas.

Hoy la Red Feminista Quintanarroense, una vez más, se levanta para hacer visible lo invisible, para hacer que las voces de las mujeres resuenen en todos los rincones de nuestro estado, y para que el Estado garantice el acceso a nuestros derechos.

El acto que hoy nos convoca es revolucionario, es contra sistema, y busca una reparación simbólica para todas nuestras hermanas que nos han sido arrebatadas víctimas de feminicidio.

Lo hacemos con nuestras manos, con nuestros esfuerzos y con nuestros recursos. Las defensoras de derechos humanos no paramos ante los obstáculos que la autoridad y la sociedad nos ha impuesto; nos revelamos ante el ineficiente trabajo de quienes deberían de dar seguridad y certeza a la vida de las mujeres.

El 29 de noviembre de 2020, en el marco de la toma pacífica del Congreso del Estado de Quintana Roo, plantábamos por primera vez en los jardines del Congreso del Estado la primera antimonumenta. Con ello, dábamos reconocimiento a las vidas de nuestras hermanas 
asesinadas, con el objetivo de que sus nombres nunca fueran olvidados y que en la historia colectiva quedaran grabados.

No obstante, el 11 de marzo de 2021, las mujeres nos levantamos con la noticia de que este símbolo de reparación simbólica había sido brutalmente atacado por quienes se esconden en el anonimato y son viles servidores del patriarcado.

Hoy 26 de junio de 2021, les estamos demostrando que no hay poder humano que detenga a las voces de las mujeres unidas. Que nos podrán derribar miles de antimonumentas más, pero estaremos de nuevo levantándonos porque nos mueve la justicia y la vida de las mujeres.

Esta Antimonumenta representa la reparación simbólica de las mujeres víctimas de feminicidio; lo hacemos como colectivas y como defensoras de derechos humanos. Este acto tiene el objetivo de permanecer en la memoria colectiva de todas y todos quienes, de ahora en adelante, miren esta Antimonumenta y recuerden los nombres de cada una de las mujeres que aquí se encuentran nombradas.

Aquí están simbólicamente representadas las hermanas que fueron asesinadas por el simple hecho de ser mujeres y vivir en un mundo de violencia e intolerancia hacia nosotras, de parte del Estado y la sociedad. Nunca podrán borrar los nombres ni las historias de vida de estas mujeres a quienes el Estado dejó en el olvido y en el abandono.

Ante esta omisión, exigimos a las autoridades que esta Antimonumenta sea reconocida como una medida de reparación simbólica para todas las mujeres que han sido víctimas de feminicidio en el estado de Quintana Roo, y que sea protegida y considerada como un recordatorio de lo que nunca más queremos padecer y de nuestro anhelo de vivir en paz.

Como señala Angela Davis, activista feminista, "No estamos aceptando las cosas que no podemos cambiar, estamos cambiando las cosas que no podemos aceptar". (Marea Verde Quintana Roo, 2021)

Cabe señalar que la Red Feminista Quintanarroense es integrante e invitada del Grupo Interinstitucional y Multidisciplinario (GIM) de seguimiento a la AVGM; en el seno del mismo, se expuso esta afrenta, por lo que se logró que, en el primer dictamen sobre la implementación de medidas establecidas en la Declaratoria de AVGM, aprobado en la décimo 
quinta sesión ordinaria del GIM, llevada a cabo el 22 de julio de 2021, se mencionara que:

Durante el mes de junio de 2021, la Antimonumenta fue reinstalada por lo que el estado podría implementar un posicionamiento para señalar que la misma es parte de esta reparación simbólica que desde la sociedad civil organizada se está efectuando, y desarrollar una estrategia de vigilancia para que la misma no sea destruida nuevamente.

De igual manera, existe el interés y planeación de las colectivas feministas de instalar una réplica de la antimonumenta en cada municipio de la entidad, así como desarrollar una serie de murales en espacios públicos y paredes de casas particulares con mensajes e imágenes que evidencien la problemática existente y se sensibilice a la población sobre el tema.

De igual manera, en el municipio de Tulum las colectivas organizadas, poniendo sus recursos y su tiempo, elaboraron un mural en memoria de Victoria, la mujer asesinada a manos de elementos policiacos, que se sugiere el Ayuntamiento pueda preservar ante actos vandálicos, en virtud del símbolo que representa.

En ese sentido, se considera que las antimonumentas y los murales pudieran constituir parte de esa reparación simbólica que no implicaría la inversión de recursos para el estado, posicionándose y reconociéndolo como reparación simbólica, así como desarrollar una estrategia para protegerlos y preservarlos.

Es importante destacar que las reparaciones simbólicas, tal y como lo informa el estado, son medidas que buscan revertir el olvido e individualidad a las que suele marginarse a quienes son víctimas de delito o violaciones a derechos humanos. Son específicas y de carácter no pecuniario ni indemnizatorio. Una reparación simbólica debe representar el dolor de la víctima, en un intento por unirla a su comunidad; asimismo, debe mostrar una mirada crítica al pasado, permitiendo trascender al futuro sin rencor o resentimiento.

Así, las reparaciones simbólicas buscan dignificar y reconocer a las víctimas, recordar la verdad de los hechos victimizantes y solicitar perdón y asumir la responsabilidad por parte de los victimarios.

Como una de las recomendaciones para la implementación de la medida se señala: 
- En conjunto con las asociaciones civiles y con familiares de las víctimas que lo autoricen, participen en actividades que contribuyan a dejar huella y conectar con la sociedad con acciones afirmativas;

- Desarrollar la vinculación entre las víctimas indirectas del delito de feminicidio y organizaciones de la sociedad civil, mediante mesas de trabajo que permitan planear las reparaciones simbólicas en el estado, conocer las diversas propuestas que puedan realizar, entre ellas las antimonumentas, e implementarlas. (CONAVIM, 2021, pp. 138-139)

Esto significó un gran logro para la causa, pues una de las consignas plasmadas en las antimonumentas sigue siendo que nuestros derechos no son negociables, y se refiere al derecho a decidir sobre si se quiere ser madre o no.

Hoy, en Quintana Roo, existe esperanza y felicidad al observar que la despenalización se logró en Hidalgo y Veracruz, uniéndose así a Oaxaca y Ciudad de México. Se insiste en que el derecho a decidir es una de las deudas históricas que el Estado tiene con las mujeres en todo México. Eso sin duda alienta a seguir en pie de lucha por la vía jurisdiccional, pero estableciendo la estrategia para abordar el tema desde la incidencia social y política. Se siguen sosteniendo reuniones estratégicas con tomadoras y tomadores de decisión, y sin duda se ha establecido un precedente ante las omisiones del Estado.

\section{Conclusiones}

En Quintana Roo, la lucha por la despenalización se ha dado desde distintos ámbitos, pero se fortaleció a partir de 2018, año en el que se salió a las calles por primera vez a exigir el aborto legal, seguro y gratuito, evento convocado desde Marea Verde Quintana Roo. Las feministas en Quintana Roo han soportado la estigmatización, la criminalización y la campaña de odio e intolerancia que surge desde la sociedad, amparada e incluso incentivada por el mismo Estado; sin embargo, son mujeres fuertes, preparadas y prudentes que han sabido caminar y seguir adelante a pesar de los recurrentes intentos por debilitarlas.

Se ha sentado precedente sobre la forma de ejercer el derecho de protesta y de libre manifestación de las ideas a través de las marchas, concentraciones, pronunciamientos, comunicados, conferencias de prensa, 
mesas de trabajo, plantón, toma pacífica del Congreso del estado y la puesta -dos veces- de la Antimonumenta.

Existe la consigna de no permitirse ser borradas e invisibilizadas en las leyes ni en la historia. Se está abriendo brecha para las siguientes generaciones; así como otras lucharon por los derechos de los que hoy se goza.

Se avanza paso a paso, a veces más lento y a veces un poco más rápido, pero al final nadie detendrá ya la marea verde que cada vez se hace más grande, crece y es imparable.

\section{Referencias bibliográficas}

Animal Político (2020, 23 de julio). Violencia contra mujeres e hijos aumenta 81\% durante pandemia, alertan refugios. Animal Político. https:// www.animalpolitico.com/2020/07/violencia-mujeres-hijos-aumenta-pandemia-refugios /

Briceño, R. (2019, 30 de mayo). Activistas del colectivo Marea Verde, piden a Carlos Joaquín que aplique acción contra integrantes de la XV Legislatura por negarse a analizar reforma de ley para despenalizar el aborto en QR. Noticaribe. https://noticaribe.com.mx/2019/05/30/ activistas-del-colectivo-marea-verde-piden-a-carlos-joaquin-que-aplique-accion-contra-integrantes-de-la-xv-legislatura-por-negarse-a-analizar-reforma-de-ley-para-despenalizar-elaborto-en-qr/

Chán, M. (2020, 25 de noviembre). Mujeres mayas marcharán para la erradicación de la violencia. Turquesa News. https://turquesanews.mx/ felipe-carrillo-puerto/mujeres-mayas-marcharan-para-la-erradicacion-de-la-violencia/

Comisión Nacional para Prevenir y Erradicar la Violencia Contra las Mujeres (2021). Primer dictamen sobre la implementación de medidas establecidas en la Declaratoria de AVGM, emitida para los Municipios de Benito Juárez, Cozumel y Solidaridad, y con medidas específicas para Lázaro Cárdenas en Q. Roo.

Comisión Nacional para Prevenir y Erradicar la Violencia Contra las Mujeres (2016). Solicitud de Alerta de Violencia de Género contra las Mujeres en el estado de Quintana Roo. Gobierno de México. https://www. gob.mx/conavim/documentos/solicitud-de-alerta-de-violencia-de-genero-contra-las-mujeres-en-el-estado-de-quintana-roo

Comisión Nacional para Prevenir y Erradicar la Violencia Contra las Mujeres 
y Secretaría de Gobernación (2017). Declaratoria de la Alerta de Violencia de Género contra las Mujeres en el Estado de Quintana Roo. https://www.gob.mx/cms/uploads/attachment/file/238267/ Declaratoria_Quintana_Roo.pdf

Congresoqroo (2020a, 13 de marzo). Intervención de la Parlamentaria Erika Lizbeth Cornelio Ramos, Distrito XIV (12/Mar/2020) [Video]. YouTube. https://www.youtube.com/watch?v=r9ysqa_xs0U

Congresoqroo (2020b, 13 de marzo). Intervención de la Parlamentaria Martha Verónica Kú Martínez, Distrito XIII (12/Mar/2020) [Video]. YouTube. https://www.youtube.com/watch?v=tIqNjuJyw20

Congresoqroo (2020c, 13 de marzo). Intervención de la Parlamentaria Sandra María Gpe. Cortes González, Othón P. Blanco (12/Mar/2020) [Video]. YouTube. https://www.youtube.com/watch?v=oAmSPU1Uo-Y

Congresoqroo (2020d, 13 de marzo). Intervención de la Parlamentaria Yunitzilim Rodríguez Pedraza, Distrito XV (12/Mar/2020) [Video]. YouTube. https://www.youtube.com/watch?v=hFh0NbmPOUw

El Universal (2020, 10 de noviembre). Lo que sabemos del feminicidio de Alexis en Quintana Roo. El Universal. https://www.eluniversal.com.mx/ estados/lo-que-sabemos-del-feminicidio-de-alexis-en-quintana-roo

Garita, N. (2019). Prólogo. En M. Larrondo y C. Ponce (eds.), Activismos feministas jóvenes: Emergencias, actrices y luchas en América Latina (pp. 11-20). CLACSO.

Larrondo, M. y Ponce, C. (2019). Activismos feministas jóvenes en América Latina. Dimensiones y perspectivas conceptuales. En M. Larrondo y C. Ponce (eds.), Activismos feministas jóvenes: emergencias, actrices y luchas en América Latina (pp. 21-40). CLACSO.

López Pérez, E. (2021, 2 de marzo). 1.4 millones de embarazos no deseados por falta de atención médica para mujeres ante COVID: ONU. El Financiero. https://www.elfinanciero.com.mx/salud/1-4-millones-de-embarazos-no-deseados-por-falta-de-atencion-medica-para-mujeres-ante-covid-onu/

Macronews (2020, 13 de marzo). Presentan iniciativa para despenalización del aborto en Quintana Roo. Macronews Noticias Cancún. https:// macronews.mx/estado/quintana-roo/presentan-iniciativa-para-despenalizacion-del-aborto-en-quintana-roo/

Maldonado, J. (2020, 22 de enero). Admite Segob solicitud de Alerta de Violencia de Género en OPB y FCP. La Jornada Maya. https://www. 
lajornadamaya.mx/quintanaroo/167594/admite-segob-solicitudde-alerta-de-violencia-de-genero-en-opb-y-fcp

Maldonado, J. (2019, 12 de junio). Reinstala UQROO a maestra cesada. La Jornada Maya. https://www.lajornadamaya.mx/quintana-roo/123755/ Reinstala-UQROO-a-maestra-cesada

Maldonado, J., Ruiz, R. y Ramírez, A. (2020, 26 de noviembre). Feministas anuncian plantón para que diputados retomen el tema del aborto. La Jornada Maya. https://lajornadamaya.mx/pdf/LJM-QRoo-26112020.pdf

MarcrixNoticias (2020,2 de octubre). Diputado Luis Guillén a favor de despenalizar el aborto. MarcrixNoticias. https://www.marcrixnoticias. com/diputado-luis-guillen-a-favor-de-despenalizar-el-aborto/

Marea Verde Quintana Roo (2021, 26 de junio). Presentación de la renacida antimonumenta como representación de la reparación simbólica por los feminicidios en Quintana Roo [Video]. Facebook. https://www.facebook.com/MareaVerdeQuintanaRoo/videos/487509785663675/

Marea Verde Quintana Roo (2020a, 25 de noviembre). [Día Internacional de la eliminación de la Violencia contra la Mujer] [Video]. Facebook. https://www.facebook.com/MareaVerdeQuintanaRoo/ videos/455543768766314/

Marea Verde Quintana Roo (2020b, 7 de marzo). El día de ayer 7 de marzo, las integrantes de la colectiva Foráneas Seguras y compañeras de José María Morelos [Publicación]. Facebook. https://www.facebook.com/ MareaVerdeQuintanaRoo/posts/674276693323490

Marea Verde Quintana Roo (2019a, 22 de octubre). Foro de discusion: la interrupción legal del embarazo en Quintana Roo. Un tema en la agenda legislativa nacional [Video]. Facebook. https://www.facebook.com/ MareaVerdeQuintanaRoo/videos/2320962398234054/

Marea Verde Quintana Roo (2019b, 14 de julio). Concluimos hoy el 3er Encuentro Regional \#HablemosDeAborto en Chetumal [Publicación]. Facebook. https://www.facebook.com/MareaVerdeQuintanaRoo/ posts/501452063939288

Marea Verde Quintana Roo (2019c, 25 de marzo). Intolerable que instituciones del Estado emitan esta serie de mensajes [Publicación]. Facebook. https:// www.facebook.com/MareaVerdeQuintanaRoo/posts/434448140639681

Montiel, A. (2019, 7 de julio). Anuncian encuentro regional sobre el aborto. RadioFormulaQR. https://radioformulaqr.com/noticias/anuncian-encuentro-regional-sobre-el-aborto/ 
Radio Mitre (2019, 9 de mayo). México: Una diputada propuso esterilizar a las mujeres que aborten. Radio Mitre. https://radiomitre.cienradios.com/mexico-una-diputada-propuso-esterilizar-las-mujeres-aborten/

Varillas, A. (2021, 11 de marzo). Destruyen "Antimonumenta" montada en el Sendero de la Igualdad en Quintana Roo. El Universal. https://www. eluniversal.com.mx/estados/destruyen-antimonumenta-montada-en-el-sendero-de-la-igualdad-en-quintana-roo

Varillas, A. (2020, 17 de noviembre). Red Feminista presenta pliego de demandas al gobernador de Quintana Roo. El Universal. https:// www.eluniversal.com.mx/estados/red-feminista-presenta-pliego-de-demandas-al-gobernador-de-quintana-roo

Varillas, A. (2019a, 1 de octubre). Aborto, la discusión pendiente en Quintana Roo. RadioFórmula QR. https://radioformulaqr.com/noticias/ opinion/adriana-varillas/aborto-la-discusion-pendiente-en-quintana-roo/

Varillas, A. (2019b, 12 de julio). Aborto en Quintana Roo, derecho no garantizado. Cimac Noticias. https://cimacnoticias.com.mx/2019/07/12/ aborto-en-quintana-roo-derecho-no-garantizado

Varillas, A. (2019c, 6 de mayo). Propone esterilizar a mujeres que aborten dos veces. El Universal Querétaro. https://www.eluniversalqueretaro.mx/nacion/diputada-propone-esterilizar-mujeres-que-aborten-por-segunda-vez

Voces Feministas (2021, 11 de marzo). Destruyen antimonumenta en Quintana Roo. VocesFeministas.mx. https://vocesfeministas.mx/destruyen-antimonumenta-en-quintana-roo/

XV Legislatura (2019, 13 de marzo). Orden del Día. Sesión número 09 del segundo periodo ordinario de sesiones del tercer año de ejercicio constitucional. Congreso de Quintana Roo. https://congresoqroo. gob.mx/ordenesdia/579/ 